\title{
Correspondence
}

\section{Sliding of the skin over subcutaneous tissue is another important factor in epidural catheter migration}

To the Editor:

An 18 gauge Portex ${ }^{\circledR}$ multipore epidural catheter was inserted in the right lateral position in an obese (body mass index 31.3) full-term primigravida using a midline approach. The catheter was threaded $4 \mathrm{~cm}$ inside the epidural space. The epidural provided pain relief for only two hours and became ineffective. Upon inspection, the insertion site was found to be $1.75 \mathrm{~cm}$ left of the midline. We propose that sliding of the skin from side to side was responsible for catheter migration (Figure).

Different factors have been proposed to explain catheter migration in or out of the epidural space. Epidural catheters may migrate appreciably despite efforts to secure them at the surface of the skin. ${ }^{1}$ For thoracic epidurals, migration is more common in patients operated in the lateral position. ${ }^{2}$ Migration of catheters related to changes in position is more important in obese compared to non obese patients. ${ }^{3}$ Catheter migration has been related to flexion and extension of the spine. ${ }^{4}$ Iwama and Katayama ${ }^{5}$ noticed $3 \mathrm{~cm}$ skin movements in some patients. To avoid the tendency of epidural catheters to "walk", they routinely place catheters $7 \mathrm{~cm}$ in the epidural space.

Besides the effects of gravity, the Figure shows how the skin can slide further towards the dependent side when the patient is asked to move towards the edge of the bed. Tendency of the catheter to be displaced because of movement cannot be avoided completely by fixing the catheter to the skin and some provision should be made for skin movement during the course of epidural analgesia.

We agree with Iwama and Katayama ${ }^{5}$ to leave the multipore epidural catheters $7 \mathrm{~cm}$ inside the epidural space. In morbidly obese patients, it might be appropriate to insert catheters even further. Finally, before fixing the catheter the patient should be allowed to return to a neutral, relaxed position. ${ }^{3}$

Mohammad Faheem MBBS FFARCSI DEAA

Nadeem Sarwar MBBS

Roscommon, Ireland
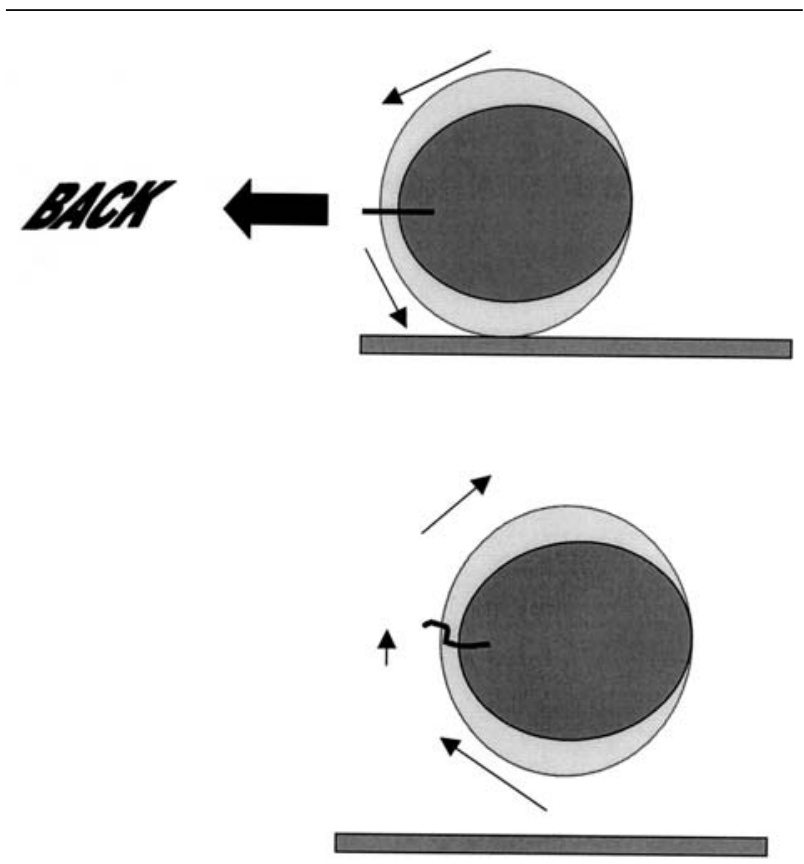

FIGURE Upper; epidural catheter in midline after insertion in the right lateral position. Note movement of the skin (fine arrows) due to gravity and to sliding (block arrow) of the patient on the bed. Lower; the skin regains a neutral position (fine arrows) after the procedure, shifting the epidural insertion site lateral to the midline. If the catheter is fixed to the skin, it may be pulled out of the epidural space. If the catheter is not fixed to the skin when the patient is repositioned after the procedure, the ligamentum flavum can maintain the catheter in place.

\section{References}

1 Bishton IM, Martin PH, Vernon JM, Lin WH. Factors influencing epidural catheter migration. Anaesthesia 1992; 47: 610-2.

2 Hendriks GW, Hasenbos MA, Gielen MJ, van Egmond J, Barentsz JO. Evaluation of thoracic epidural catheter position and migration using radio-opaque catheters. Anaesthesia 1997; 52: 457-9.

3 Hamilton CL, Riley ET, Cohen SE. Changes in the position of epidural catheters associated with patient movement. Anesthesiology 1997; 86: 778-84.

4 Dunbar $S$. Migration of an epidural catheter related to flexion and extension of the spine. Anesth Analg 1993; 76: 906.

5 Iwama H, Katayama T. Back skin movement also causes "walking" epidural catheter. J Clin Anesth 1999; 11: 140-1. 